\title{
Disrupting Effect of Drug-Induced Reward on Spatial But Not Cue-Guided Learning: Implication of the Striatal Protein Kinase A/cAMP Response Element-Binding Protein Pathway
}

\author{
Mathieu Baudonnat, ${ }^{1,2}$ Jean-Louis Guillou, ${ }^{1,2}$ Marianne Husson, ${ }^{1,2}$ Matthias Vandesquille, ${ }^{1,2}$ Marc Corio, ${ }^{1,2}$ \\ Laurence Decorte, ${ }^{1,2}$ Angélique Faugère, ${ }^{1,2}$ Yves Porte, ${ }^{1,2}$ Nicole Mons, ${ }^{1,2}$ and Vincent David ${ }^{1,2}$ \\ 'Université de Bordeaux and 'Institut de Neurosciences Cognitives et Intégratives d'Aquitaine, Centre National de la Recherche Scientifique, Unité Mixte de \\ Recherche 5287, 33405 Talence, France
}

\begin{abstract}
The multiple memory systems hypothesis posits that different neural circuits function in parallel and may compete for information processing and storage. For example, instrumental conditioning would depend on the striatum, whereas spatial memory may be mediated by a circuit centered on the hippocampus. However, the nature of the task itself is not sufficient to select durably one system over the other. In this study, we investigated the effects of natural and pharmacological rewards on the selection of a particular memory system during learning. We compared the effects of food- or drug-induced activation of the reward system on cue-guided versus spatial learning using a Y-maze discrimination task. Drug-induced reward severely impaired the acquisition of a spatial discrimination task but spared the cued version of the task. Immunohistochemical analysis of the phosphorylated form of the cAMP response element binding (CREB) protein and c-Fos expression induced by behavioral testing revealed that the spatial deficit was associated with a decrease of both markers within the hippocampus and the prefrontal cortex. In contrast, drug reward potentiated the cued learning-induced CREB phosphorylation within the dorsal striatum. Administration of the protein kinase A inhibitor 8-Bromo-adenosine-3', 5'-cyclic monophosphorothioate Rp isomer (Rp-cAMPS) into the dorsal striatum before training completely reversed the drug-induced spatial deficit and restored CREB phosphorylation levels within the hippocampus and the prefrontal cortex. Therefore, drug-induced striatal hyperactivity may underlie the declarative memory deficit reported here. This mechanism could represent an important early step toward the development of addictive behaviors by promoting conditioning to the detriment of more flexible forms of memory.
\end{abstract}

\section{Introduction}

Different types of memory are processed in the mammalian brain. A declarative/cognitive memory system relying on hippocampal and prefrontal cortex (PFC) circuitry allows the encoding and recall of events in a flexible manner (Eichenbaum et al., 1990; Squire, 1998), whereas procedural/response memory concerning motor skills, habits, and stimulus-response (S-R) associations depends on the dorsal striatum (STR) (Reading et al., 1991; McDonald and White, 1994; Martel et al., 2007; Lee et al., 2008). Dorsal STR supports two forms of instrumental learning described in rodents as well as in humans: the goal-directed behavior mediating action-outcome associations and the S-R habit processing (Dickinson and Balleine, 1990). Hippocampusand striatum-centered memory systems may operate either cooperatively (McDonald et al., 2004; Voermans et al., 2004) or

\footnotetext{
Received April 6, 2011; revised Aug. 9, 2011; accepted Sept. 10, 2011.

Author contributions: M.B. and V.D. designed research; M.B., M.H., M.V., M.C., L.D., A.F., Y.P., N.M., and V.D. performed research; M.B., J.-L.G., and V.D. analyzed data; M.B., J.-L.G., and V.D. wrote the paper.

Wethank Nadia Henkous for her technical assistance regarding these experiments. We also thank Gilles Courtand for his technical support for image analysis.

Correspondence should be addressed to Vincent David, Université de Bordeaux, Institut de Neurosciences Cognitives et Intégratives d'Aquitaine, CNRS, UMR 5287, Avenue des Facultés, 33405 Talence, France. E-mail: vincent.david@u-bordeaux1.fr.

DOI:10.1523/JNEUROSCI.1787-11.2011

Copyright $\odot 2011$ the authors $\quad 0270-6474 / 11 / 3116517-12 \$ 15.00 / 0$
}

competitively to optimize behavior (Packard, 1999; Poldrack and Packard, 2003). Time, training, and stress are significant modulating factors prompting the use of habit, striatal system over hippocampus-dependent learning (Kim et al., 2001; Kim and Diamond, 2002; Sandi and Pinelo-Nava, 2007; Schwabe et al., 2007, 2010a). Surprisingly, little is known about the impact of hedonic arousals on memory systems interactions.

There is compelling evidence that the mesolimbic dopamine (DA) system, constituted of neurons projecting from the ventral tegmental area (VTA) to the nucleus accumbens (NAc), is critically involved in mediating the rewarding effects of food and drugs of abuse (Bromberg-Martin et al., 2010). DA plays also an essential role in reinforcement learning by facilitating heterosynaptic plasticity at corticostriatal synapses (Montague et al., 1996; Suri and Schultz, 1999; Reynolds et al., 2001). Given that VTA neurons target memory-relevant brain regions, such as the striatum, hippocampus, or the PFC (Fallon et al., 1978; Oades and Halliday, 1987; Gasbarri et al., 1996; Lammel et al., 2008), DA could modulate or "stamp-in" different memory traces of the behavioral sequence leading to the receipt of rewards (Wise, 2004).

DA released postsynaptically links G-protein-coupled receptors, which in turn activate the protein kinase A (PKA) pathway, eventually leading to the phosphorylation of the cAMP response element-binding protein (CREB) family of transcription factors 
(Dudman et al., 2003; Arnsten et al., 2005). Extensive evidence supports a critical role of the phosphorylated form of CREB (pCREB) in reinforcement learning (Kelley, 2004; Hyman et al., 2006) and more generally in long-term memory formation through the induction of c-Fos and other transcription factors (Colombo et al., 2003). Decrease of pCREB protein level disrupts spatial memory (Bourtchuladze et al., 1994; Guzowski and McGaugh, 1997), whereas increased CREB phosphorylation enhances the formation of long-term memory (Josselyn et al., 2001). Specific forms of memory seem to depend on regional expression of pCREB (Colombo et al., 2003). Reversible inhibition of CREB in the dorsal hippocampus (CA1 region) impairs spatial memory, whereas alteration of striatal synaptic plasticity through transgenic inhibition of CREB impairs cued learning (Pittenger et al., 2002; Lee et al., 2008).

Here we have investigated the effects of food- and druginduced activation of the reward system on spatial or cue-guided learning. To reveal synaptic plasticity-related cellular signaling depending on the learning strategy and the type of reward, we measured regional pCREB expression in the brains of mice after behavioral assessment of learning. To determine whether the activation pattern of brain regions involved was strictly CREB specific, we also performed c-Fos immunolabeling experiments. Finally, we tested whether cognitive, spatial performance could be improved with pharmacological inhibition of the PKA/CREB pathway within the dorsal STR.

\section{Materials and Methods}

\section{Subjects}

Male mice of C57BL/6J strain (13 weeks old and 25-30 g at arrival; Charles River) were housed individually and were maintained on a $12 \mathrm{~h}$ light/dark artificial cycle (lights on at 7:00 A.M.), in a temperaturecontrolled colony room $\left(22 \pm 1^{\circ} \mathrm{C}\right)$ and were provided with food and water ad libitum. One week before the beginning of the behavioral testing, the food ration was adjusted individually so that all mice had reached $95 \%$ of their ad libitum weights and was maintained for the entire Y-maze task. All surgical and experimental procedures were conducted in accordance with the European Communities Council Directive of November 24, 1986 (86/069/EEC).

\section{Y-maze task}

Surgery. Subjects were anesthetized with a ketamine/xylazine mixture [Ketamine 1000 (Virbac), $100 \mathrm{mg} / \mathrm{kg}$, i.p./2\% Rompun, $8 \mathrm{mg} / \mathrm{kg}$, i.p.], and lidocaine $\mathrm{HCl}$ (5\% Xylocaine) was applied locally before opening the scalp and trepanation. Animals were implanted unilaterally in a counterbalanced left and right order. It has been demonstrated previously that the magnitude of the motivational effect of unilaterally applied opioids into the VTA was similar to that observed when bilateral injections were used (Phillips and LePiane, 1980; Bozarth, 1987). The tip of the guide cannula $(0.460 \mathrm{~mm}$ outer diameter or 25 gauge; $0.255 \mathrm{~mm}$ inner diameter or 30 gauge) was positioned $1.5 \mathrm{~mm}$ above the VTA according to the following stereotaxic coordinates: $0.40 \mathrm{~mm}$ anterior to the interaural line, $\pm 0.30 \mathrm{~mm}$ lateral to the sagittal line, and $3.30 \mathrm{~mm}$ vertically below the surface of the skull. The incisor bar was leveled with the interaural line. Mice were allowed to recover from surgery for at least 1 week. All surgical implantations were controlled after experiments using thionine blue coloration on $50 \mu \mathrm{m}$ coronal brain sections and visualized under optical microscope. Implantation sites are schematized in Figure 1.

Apparatus. Behavioral experiments were conducted in a gray Plexiglas Y-maze, the arms of which were separated by an angle of $120^{\circ}$. The stem and the arms were $31 \mathrm{~cm}$ long and $12 \mathrm{~cm}$ high. The starting box $(14 \times 8$ $\mathrm{cm}$ ) was separated from the stem by a sliding door. Each arm was composed of a sliding door at its entrance and a photoelectric cell $6 \mathrm{~cm}$ from its end. On each day of the Y-maze experimental period, stainless-steel injection cannula $(0.299 \mathrm{~mm}$ outer diameter or 31 gauge $31 ; 0.127 \mathrm{~mm}$ inner diameter or 36 gauge) was inserted into the VTA and was held in a
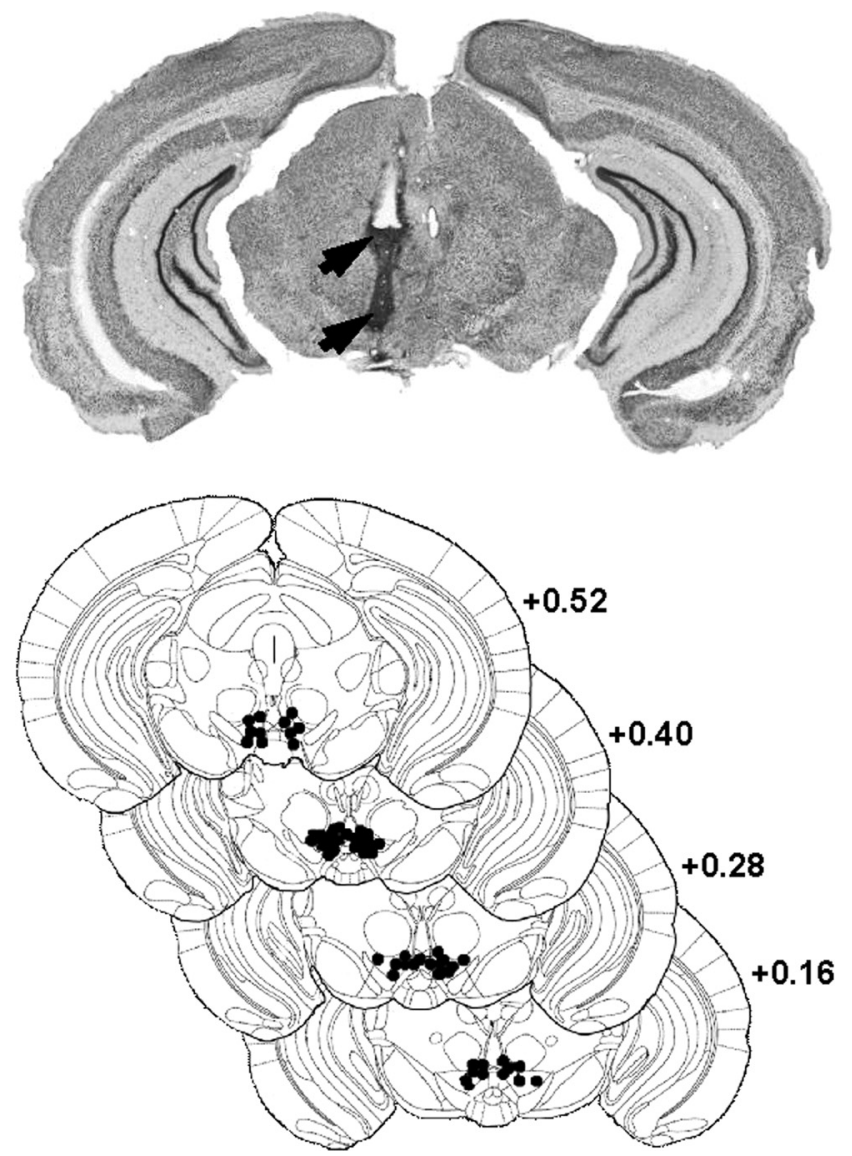

Figure 1. Localization of injection sites in the VTA. Top, Wide representative microphotographic view of one injection site, showing traces left by the guide cannula (top arrow) and injection cannula (bottom arrow). Bottom, Histological control of all stereotaxically implanted mice. Black dots show locations of the tip of the cannula (stereotaxic coordinates: anteroposterior, $+0.4 \mathrm{~mm}$ from interaural; mediolateral, $\pm 0.3 \mathrm{~mm}$; dorsoventral, $+3.3 \mathrm{~mm}$ ). Distribution of self-injection sites corresponds mainly to the posteromedial VTA projection system (Ikemoto, 2007).

fixed position, by means of a small connector. The injection cannula was connected by a flexible polyethylene tubing to the microinjection system, which housed a $5 \mu$ l Hamilton syringe. The tip of the injection cannula projected beyond the guide cannula by $1.5 \mathrm{~mm}$. By interrupting the photocell beam in one of the two target arms, mice could obtain a $5 \mathrm{~mm}^{2}$ crisp or trigger an intra-VTA microinjection of morphine sulfate dissolved in artificial CSF (aCSF) (50 ng/50 nl). The other arm was neutral. Mice were maintained for $30 \mathrm{~s}$ in the chosen arm. Intracranial injections were performed using an automatic computer-controlled apparatus, which provided, via a microvernier system, a precise and highly reproducible descent of the microsyringe piston. Each self-injection (50 nl) lasted $8 \mathrm{~s}$. Normal injection flow was verified visually both before and after each Y-maze trial for each animal. The movements of the animal in the Y-maze were detected using an optical system. This information was transmitted to a microcomputer, which in turn rotated the injector in the same direction as each animal's movement. This process avoided the twisting of the flexible tubing. The number of correct choices per daily session was noted, and automatic equipment, triggered by opening the door to the stem, recorded the latency to enter the reinforced or the neutral arm (response latency) for each subject.

Choice of rewards. Small pieces $\left(\sim 5 \mathrm{~mm}^{2}\right)$ of naturally flavored crisps (Vico) were chosen as food reward after pilot studies showing that motivation to learn the task was obtained with a very low level of deprivation $(<5 \%)$. Therefore, the same level of deprivation was applied to all groups to ensure a comparable physiological state in all animals. Intracranial drug self-administration was used as a model of reinforcement learning 

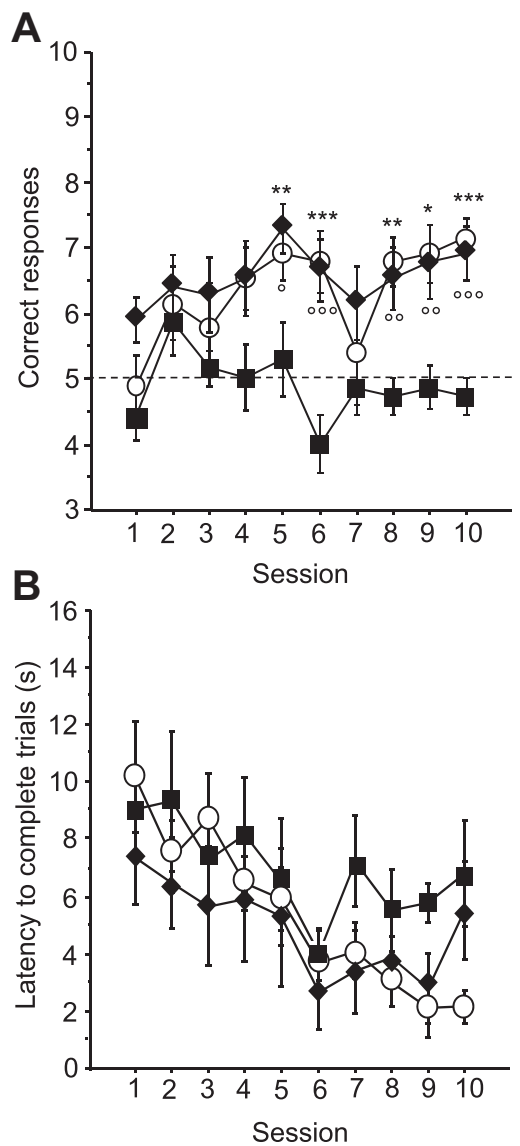

Figure 2. Acquisition of the cue-guided Y-maze protocol expressed as the mean \pm SEM number of correct responses over 10 training sessions (10 trials/d). $A$, Both natural (crisps group, white dots) and pharmacological (morphine group, black diamonds) rewards allowed the acquisition of this task compared with aCSF (black squares) control group (aCSF vs crisps group: ${ }^{*} p<0.05,{ }^{* *} p<0.01,{ }^{* * *} p<0.001$; aCSF vs morphine group: ${ }^{\circ} p<0.05,{ }^{\circ 0} p<0.01,{ }^{\circ 00} p<$ $0.001) . B$, Analysis of mean \pm SEM latencies to complete a trial (in seconds) over the 10 training sessions (session effect, $p<0.001$ ).

similarly to intracranial self-stimulation (Reynolds et al., 2001). This model presented several advantages. Food or drugs were selfadministered in the same conditions, avoiding manipulation during behavioral tests and thus allowing direct comparison of learning in drugand food-reinforced animals. We used morphine as a mean to activate pharmacologically VTA-DA neurons (Matthews and German, 1984; Johnson and North, 1992; Nugent et al., 2007), without altering directly function in all brain regions (McBride et al., 1999). The dose of morphine was selected on the basis of optimal learning performances established in dose-effect curves reported previously using an egocentric/procedural version of the same arm-discrimination task (David et al., 2002, 2008).

Habituation procedure. Before the beginning of the task, all animals were submitted to a habituation session during which they were connected to the self-administration apparatus and placed in the maze for a $10 \mathrm{~min}$ freely visit (no injections or cues).

$Y$-maze cue-guided task. Seventy-two hours after the habituation session, animals were separated into three groups corresponding to a particular type of reward: one group of mice was reinforced with intra-VTA morphine (cued-morphine, $n=8$ ). The second group was reinforced with crisps (cued-crisps, $n=8$ ). The last one was a control group receiving intra-VTA aCSF (cued-aCSF, $n=7$ ). In addition, another control group of animals underwent training in the same procedure except that they could not control injections in the maze (cued-yoked: $n=6$; see yoked procedure below). Animals submitted to the cue-guided strategy had to associate a visual intramaze cue (black-white striped paper) with the delivery of the reward. The goal arm and the starting arm were pseudorandomized to avoid egocentric strategy. Training lasted $10 \mathrm{~d}$, during

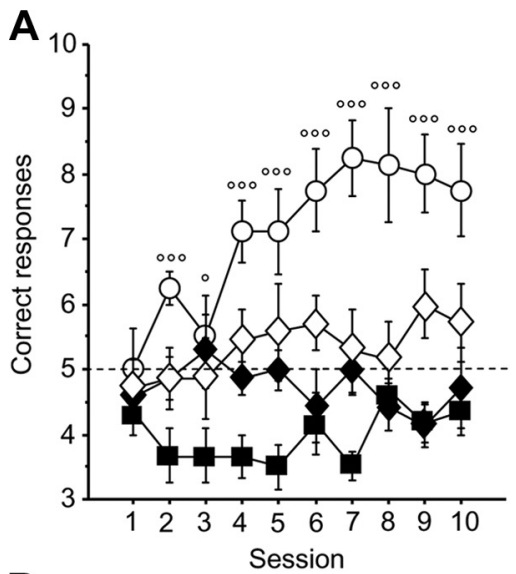

B

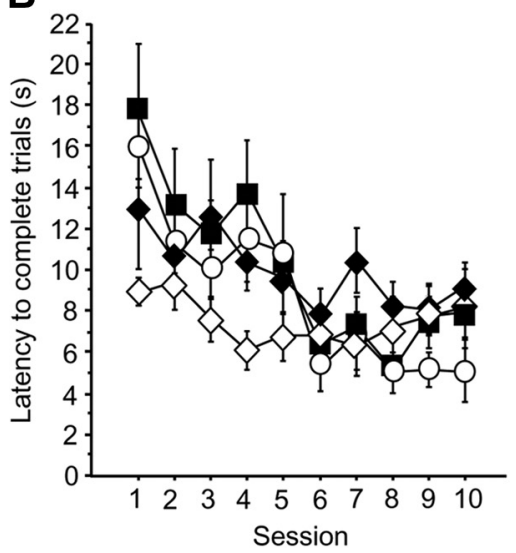

Figure 3. Acquisition of the spatial Y-maze protocol expressed as mean \pm SEM correct responses over 10 training sessions ( 10 trials/d). $\boldsymbol{A}$, Mice reinforced with crisps (white dots) rapidly learned to locate the rewarded arm, exhibiting more correct choices than the three other groups ( $p<0.001$; crisps vs morphine: ${ }^{\circ} p<0.05,{ }^{\circ 00} p<0.001$ ) (morphine group, black diamonds; morphine- crisps group, white diamonds; a(SF group, black squares). $\boldsymbol{B}$, Analysis of mean \pm SEM latency to complete a trial (in seconds) over the 10 training sessions in the $Y$-maze (session effect, $p<0.001$ ).

which animals had to enter the reinforced arm for 10 trials per daily session.

$Y$-maze spatial task. Seventy-two hours after the habituation session, animals were separated into four groups corresponding to a particular type of reward: one group received intra-VTA morphine injections (spatial-morphine; $n=7$ ), the second group could eat a $5 \mathrm{~mm}^{2}$ piece of crisp (spatial-crisps; $n=8$ ), and a third group received both rewards concurrently (spatial-morphine-crisps; $n=7$ ). The last control group received intra-VTA aCSF (spatial-aCSF, $n=6$ ). Finally, we also included a group of yoked animals that did not control their injections in the maze (spatial-yoked; $n=5$ ). Training lasted $10 \mathrm{~d}$, during which animals had to enter the reinforced arm for 10 trials per daily session. The order of starting arm was pseudorandomized among trials to avoid development of learning based on an egocentric strategy. There were no visual intramaze cues, so mice had to rely on spatial location, extramaze cues, as well as undetected intramaze, proprioceptive or interoceptive stimuli to navigate within the maze and find the rewarded arm. It is well established that processing of multiple converging stimuli requires the involvement of the hippocampus, which mediates the coding of relationships between events (Eichenbaum et al., 1990).

Procedure used for yoked control groups. Yoked animals were submitted to the same protocol as other trained animals: there were connected to the self-administration system and placed into the start arm of the Y-maze, and the session began exactly as with either the cued (cueyoked) or spatial (spatial-yoked) learning protocol. Yoked subjects in the cued training had the same visual cue (intramaze black and white striped paper) as the paired mice. Yoked animals in the spatial condition relied 

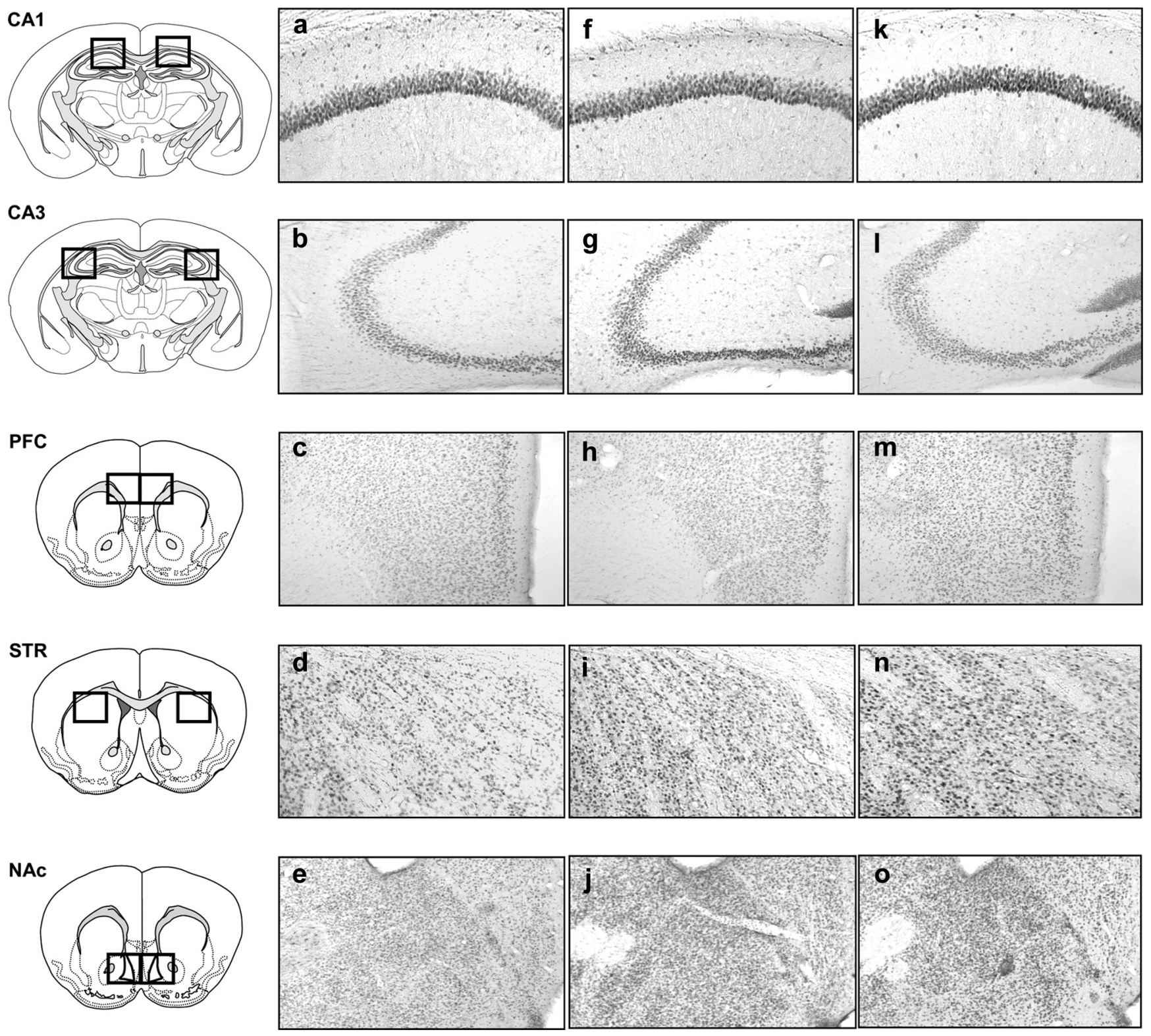

Figure 4. Representative photomicrographs of pCREB immunopositive neurons within the CA1 subfield of the hippocampus (CA1), the CA3 subfield of the hippocampus (CA3), the prelimbic part of the PFC, the dorsal STR, and the NAc consequently to the cue-guided protocol: $\boldsymbol{a}-\boldsymbol{e}, \mathrm{aCSF}$ group; $\boldsymbol{f}-\boldsymbol{j}$, crisps group; $\boldsymbol{k}-\boldsymbol{o}$, morphine group ( $\times 10$ magnification).

on extramaze cues as visual stimuli. Thus, both yoked control groups were treated separately (they were not the same animals). They began each trial in the same starting arm as the self-trained animal. However, they could not trigger the injection; instead, the computer did it so yoked mice received an injection only when the paired animal found the correct arm, wherever yoked mice were in the maze. They were allowed to freely run inside the maze for $30 \mathrm{~s}$ to avoid any association between a particular location and the effects of the injection. Then, they were gently guided to the new start arm for the next trial. If the trial did not contain any injections, the mouse was allowed to run freely inside the maze as long as the trial lasts for the paired animal.

\section{Immunochemistry}

General procedure. After completion of the last training session, the brains of mice were removed to assess learning-induced brain regional expression of pCREB (Martel et al., 2006; Porte et al., 2008) and c-Fos (Colombo et al., 2003). Under anesthesia, animals were perfused transcardially with an ice-cold solution of $4 \%$ paraformaldehyde in phosphate buffer $(0.1 \mathrm{M}) \mathrm{pH}$ 7.4. Brains were then removed and postfixed overnight in the same fixative at $4^{\circ} \mathrm{C}$. Brains were then put into a saccha- rose solution ( $0.1 \mathrm{~m} 30 \%$ in phosphate buffer, $\mathrm{pH} 7.4$ ) overnight and were then frozen to cut $50 \mu \mathrm{m}$ coronal free-floating sections with a freezing microtome (Leica) in preparation for immunochemistry. After elimination of endogenous peroxidase activity by $\mathrm{H}_{2} \mathrm{O}_{2} 30 \mathrm{~min}$ incubation and a preincubation step in saturation buffer (1\% bovine serum albumin, $3 \%$ goat serum, $0.2 \%$ Triton $\mathrm{X}-100$ ), sections were incubated with primary antibody. Subsequently, sections were incubated with biotinylated goat anti-rabbit antibody (1:2000 in buffer; Jackson ImmunoResearch) and followed by an avidin-biotinylated horseradish peroxidase complex (Vectastain Elite kit; Vector Laboratories). The peroxidase reaction end product was visualized in a buffer solution containing diaminobenzidine tetrahydrochloride (5\%). Sections were mounted on gelatincoated slides, air dried, dehydrated, coverslipped with Eukitt, and examined through light microscopy. The quantification of positive nuclei was performed at $10 \times$ magnification, which yielded a field of view of $849 \times 637 \mu \mathrm{m}$, using unbiased stereology and in double blind condition to experimental procedure. At least six serial sections for each brain regions were digitized and analyzed using a computerized image analysis system (Visiolab 2000, version 4.50; Biocom). The 

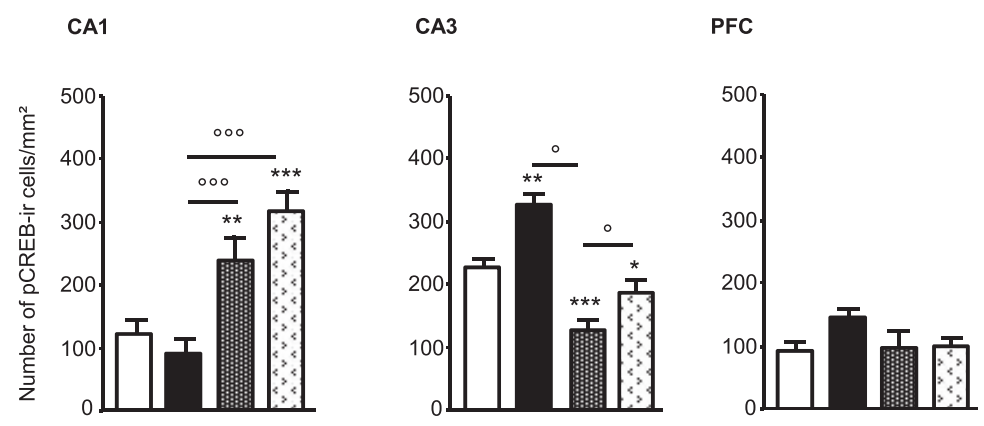

the studies using Rp-cAMPS were performed in rats, so we set up pilot experiments with C57BL/6 mice to determine injection parameters, based on the concentration ( $4 \mathrm{nmol}$ dissolved in $0.3 \mu \mathrm{l}$ of aCSF $)$ and injection time $(0.1 \mu \mathrm{l} / \mathrm{min})$ reported by Shimizu-Albergine et al. (2001). We observed that intra-hippocampal infusion of Rp-cAMPS significantly alters spatial learning in the Morris water maze without affecting motility. We thus use the same injection parameters for the present study.

Behavioral procedure. Rp-cAMPS-treated animals were tested in the spatial version of the Y-maze discrimination task described above. Ten minutes before each daily session, $\mathrm{Rp}$ cAMPS was injected into the dorsal STR of mice in their home cage. Each injection lasted 3 min. Subjects were separated into three groups: one group was injected with Rp-cAMPS and was rewarded with intra-VTA morphine ( Rpmorphine $n=6$ ); one group was injected with aCSF and was rewarded with intra-VTA morphine (aCSF-morphine $n=6$ ); and one group was injected with aCSF and was rewarded with crisps $(\mathrm{aCSF}-\operatorname{crisps} n=6)$ to serve as a positive control group. Injections occurred in freely moving animals using cannulas connected to 1 $\mu$ l Hamilton syringes with polystyrene tubing and were performed by a computerized system that provides highly precise and reproducible injection flows. Achievements of the injections

Figure 5. Region-specific patterns of CREB phosphorylation following acquisition of the cue-guided learning task. Measures are expressed as mean \pm SEM number of $p C R E B$ immunoreactive ( $p C R E B$-ir) cells per square millimeter in the CA1, CA3, PFC, STR, and NAc. Comparison with aCSF group: ${ }^{*} p<0.05,{ }^{* *} p<0.01,{ }^{* * *} p<0.001$; other comparisons: ${ }^{\circ} p<0.05,{ }^{000} p<0.001$.

number of nuclei was quantified in the following areas of interest according to Paxinos and Franklin (2001): subfields of the dorsal hippocampus (CA1, CA3), dorsal STR, shell part of the NAc, and PFC (infralimbic and prelimbic part merged). Cell counts were expressed as mean number of positive nuclei per square millimeter.

pCREB staining. Animals were killed $15 \mathrm{~min}$ after the last acquisition session. All solutions contained the phosphatase inhibitor sodium fluoride $\left(2.1 \mathrm{~g} / \mathrm{L}^{-1}\right)$ and Tris buffer $(0.1 \mathrm{M}, \mathrm{pH} 7.4)$ were used for immunochemistry. Coronal floating sections were collected in Tris buffer $(0.1 \mathrm{M})$. Sections were incubated for $48 \mathrm{~h}$ with rabbit anti-pCREB antibody (1: 6000 in saturation buffer; Millipore) at $4^{\circ} \mathrm{C}$.

c-Fos staining. Animals were killed $60 \mathrm{~min}$ after the last acquisition session. Phosphate buffer (0.1 M, pH 7.4) was used for immunochemistry. Coronal floating sections were collected in phosphate buffer $(0.1 \mathrm{M}, \mathrm{pH} 7.4)$. Sections were incubated for $24 \mathrm{~h}$ with rabbit anti-c-Fos antibody (1:8000 in saturation buffer; Santa Cruz Biotechnology) at room temperature.

\section{Inhibition of the dorso-striatal PKA/CREB activity}

Surgery. Subjects were implanted with a guide cannula $1.5 \mathrm{~mm}$ above the VTA following the procedure described previously. Two guide cannulas ( $0.460 \mathrm{~mm}$ outer diameter or 25 gauge; $0.255 \mathrm{~mm}$ inner diameter or 30 gauge) were implanted bilaterally $1 \mathrm{~mm}$ above the dorsal STR according to the following stereotaxic coordinates: $0.62 \mathrm{~mm}$ anterior to bregma, $\pm 1.9 \mathrm{~mm}$ lateral to the sagittal line, $1.5 \mathrm{~mm}$ below the skull surface. The stainless-steel injection cannula $(0.299 \mathrm{~mm}$ outer diameter or 31 gauge; $0.127 \mathrm{~mm}$ inner diameter or 36 gauge) projected $1 \mathrm{~mm}$ below the tip of the guide cannula. All surgical implantations were controlled after experiments using thionine blue coloration and visualized under optical microscope. Implantation sites are schematized in Figure $10 \mathrm{~A}$.

Intracranial infusion of the PKA/pCREB inhibitor. The 8-bromoadenosine-3', 5'-cyclic monophosphorothioate, Rp-isomer (Rp-8-BrcAMPS or Rp-cAMPS), a membrane-permeable PKA inhibitor, was used to prevent CREB phosphorylation. The choice of this molecule was based on both published evidence and a pilot study. Numerous studies have investigated the role of the cAMP-PKA pathway in learning and memory (Arnsten et al., 2005). Dudman et al. (2003) have reported that DA $D_{1}$ receptormediated CREB phosphorylation depends mainly on PKA activity. RpcAMPS can be administered intracranially to prevent brain regional CREB phosphorylation (Taylor et al., 1999; Ramos et al., 2003). However, most of were visually controlled, and injection cannulas remained connected for $2 \mathrm{~min}$. Mice were then disconnected from the injection device and waited 5 min before the Y-maze training session started. To determine levels of brain regional CREB activity, Rp-cAMPS-treated mice and controls were killed 15 min after the last Y-maze acquisition session.

\section{Statistical analysis}

Behavioral data, i.e., the mean \pm SEM number of correct responses and the choice latency, were analyzed using a two-way ANOVA with reward as between-subjects factor and session as a within-subjects repeated factor. Day-by-day between groups comparisons were performed using one-way ANOVA with reward as between-subjects factor. One-sample $t$ tests were used to compare performance on the last training session with chance level (five correct responses). The same analyses were performed on behavioral data of the PKA inhibition experiment using treatment as between-subjects factor and session as a within-subjects repeated factor.

Immunohistochemical data were expressed as mean \pm SEM IRpositive nuclei per square millimeter of both hemispheres. One-way ANOVA analyses were performed with reward as between-subjects factors for each of the brain area sampled. The same analysis was performed on the immunohistochemical data of PKA inhibition experiment but using treatment as between-subjects factor.

Post hoc analyses of significant main effects were further examined using Fisher's PLSD tests. Significance level of $p<0.05$ was used for all statistical analyses.

\section{Results}

\section{Drug- and food-reinforced mice learn the cued} discrimination task

As illustrated in Figure $2 \mathrm{~A}$, both intra-VTA morphine and crisps allowed mice to learn the cue-guided strategy compared with aCSF control mice, which exhibited a number of cue-guided responses close to chance level ( $t$ test against chance level on day 10: aCSF, $p>0.05$ ) (reward effect, $F_{(2,20)}=16.97, p<0.001$; session effect, $F_{(9,180)}=2.53 p<0.01$; reward $\times$ session interaction, $\left.F_{(18,180)}=1.09 p=0.359\right)$. Post hoc analyses revealed that cued- 

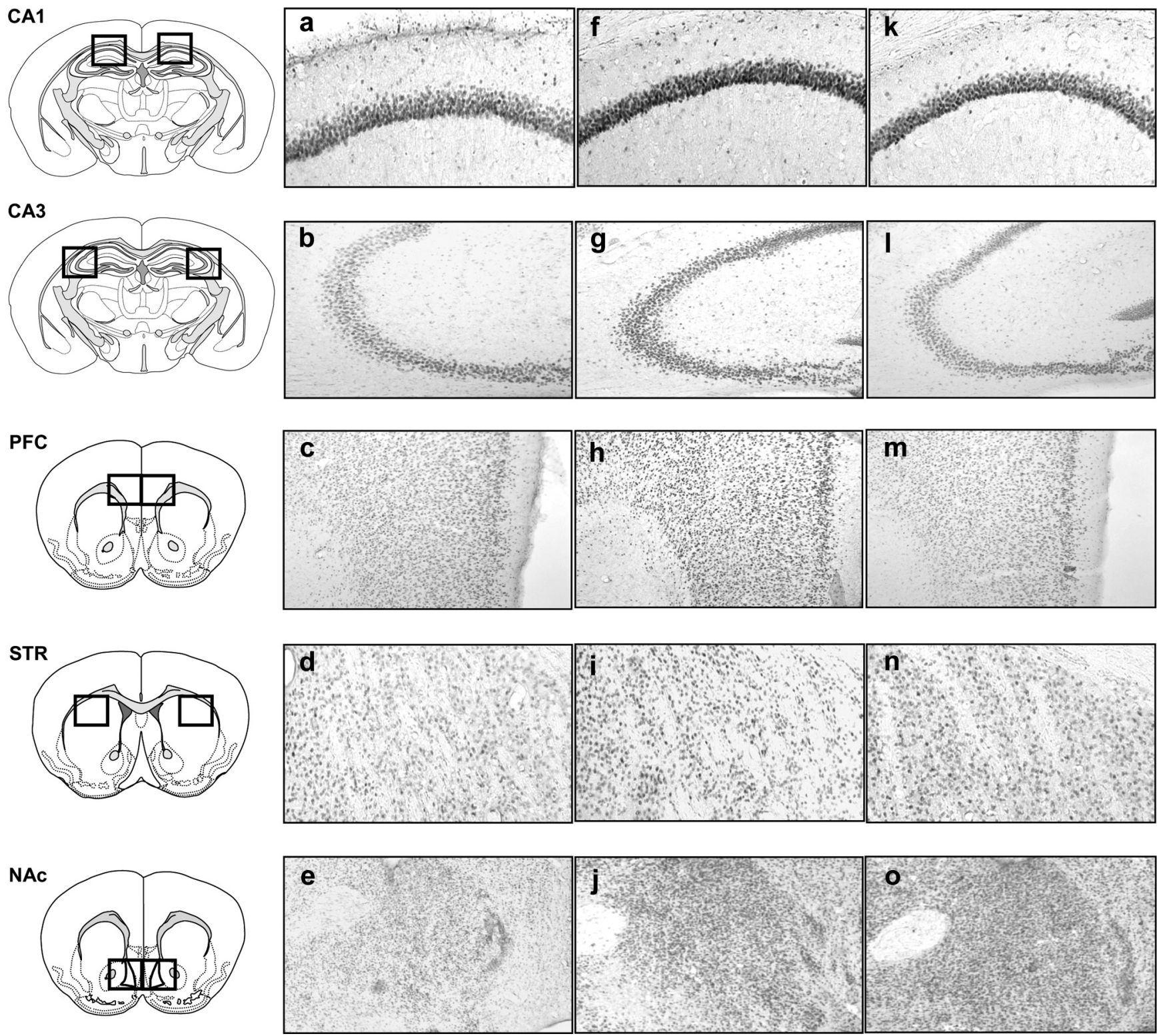

Figure 6. Representative photomicrographs of pCREB immunopositive neurons in the CA1, CA3, PFC, STR, and NAc consequently to the spatial task: $\boldsymbol{a}-\boldsymbol{e}$, aCSF group; $\boldsymbol{f}-\boldsymbol{j}$, crisps group; $\boldsymbol{k}-\boldsymbol{o}$, morphine group ( $\times 10$ magnification).

morphine mice and cued-crisps mice made more correct responses by session compared with cued-aCSF mice from day 5 to day 10 (morphine vs aCSF, $p<0.05$; crisps vs aCSF, $p<0.01$; morphine vs crisps, NS). Analysis of mean latency to complete a trial (Fig. $2 B$ ) revealed that only crisps-rewarded mice exhibited a decrease in choice latency over sessions (session effect: aCSF, $F_{(9,54)}=1.16, p=0.333$; morphine, $F_{(9,63)}=1.43, p=0.194$; crisps, $\left.F_{(9,63)}=6.48, p<0.001\right)$.

\section{Drug-reinforced mice exhibit a spatial learning deficit}

In contrast to the cued version of the discrimination task, acquisition of the spatial task was severely impaired in drug-reinforced mice, whereas the spatial version was quickly learned when crisps were given as a reward (Fig. $3 A$ ) (reward effect, $F_{(3,24)}=12.65, p<0.001$; session effect, $F_{(9,216)}=3.53, p=0.003$; reward $\times$ session interaction, $\left.F_{(27,216)}=3.07, p<0.001\right)$. Post hoc analyses revealed that crisps-rewarded mice made more correct choices than morphine, morphine-crisps, and aCSF groups, which performed at chance level ( $t$ test against chance level on day 10 : aCSF, $p<0.05$; morphine, $p>0.05$; morphine-crisps, $p>0.05$; post hoc crisps vs morphine, $p<0.001$; crisps vs morphine-crisps, $p=0.001$; crisps vs aCSF, $p<$ 0.001; morphine vs aCSF, NS; morphine vs morphine-Crisps, NS; morphine-crisps vs aCSF, $p<0.01$ ). Controls (aCSF-injected) but not morphine-injected mice were more likely to visit the arm they had not entered during trial $n-1$ (spontaneous alternation), which resulted in a performance below chance level (one-sample $t$ test against chance level over 10 sessions: aCSF, $p<0.001$ ). This observation is not surprising given that $\mathrm{C} 57 \mathrm{BL} / 6$ mice have a strong motivation to explore novel environments, a natural tendency used by numerous studies to develop non-reinforced, working memory tasks, such as the T-maze task. One-way ANOVA of mean latencies to complete a trial (Fig. 3B) revealed that morphine-crisps animals were the only group that did not decrease their choice latency over sessions within the spatial version of the task $\left(\mathrm{aCSF}, F_{(9,72)}=3.81\right.$, $p<0.001$; morphine, $F_{(9,81)}=4.26, p=0.001$; crisps, $F_{(9,81)}=7.60$, $p<0.001$; morphine-crisps, $\left.F_{(9,54)}=1.21, p=0.305\right)$. 

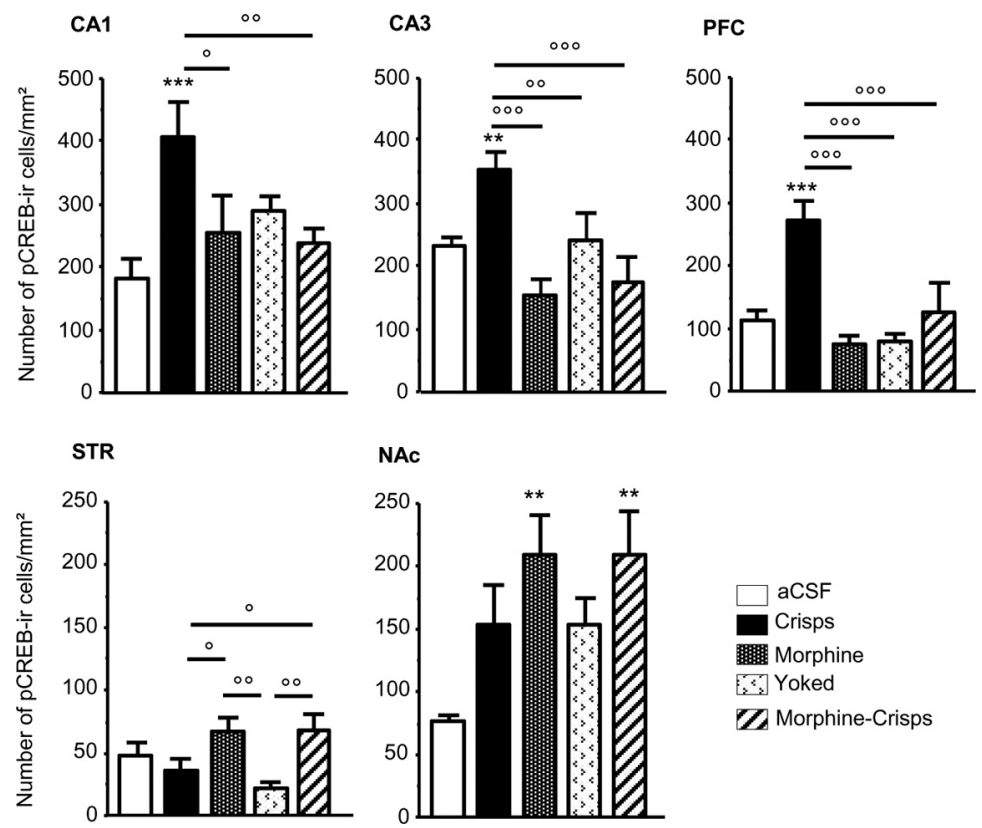

Figure 7. Region-specific patterns of CREB phosphorylation following acquisition of the spatial learning task. Measures are expressed as mean \pm SEM number of $p$ CREB immunoreactive ( $p$ CREB-ir) cells per square millimeter in the CA1, CA3, PFC, STR, and NAc. Comparison with aCSF group: ${ }^{* *} p<0.01,{ }^{* * *} p<0.001$; other comparisons: ${ }^{\circ} p<0.05,{ }^{\circ 0} p<0.01,{ }^{000} p<0.001$.

In both versions of the Y-maze discrimination task, two-way ANOVA revealed that the mean latency to complete a trial was similar in drug- and food-reinforced subjects (cue-guided strategy: reward effect, $p>0.05$; session effect, $F_{(9,180)}=5.97, p<$ 0.001; spatial strategy: reward effect, $p>0.05$; session effect, $\left.F_{(9,24)}=13.21, p<0.001\right)$.

\section{Brain regional expression of pCREB: cue-guided discrimination task}

The brain regional pattern of pCREB expression induced by the acquisition of the cue-guided task depended on the type of reward (Figs. 4, 5). Both food- and drug-reinforced mice exhibited a significant increase of CREB phosphorylation in the dorsal STR (reward effect, $F_{(3,25)}=26.88, p<0.001$; post hoc crisps vs aCSF, $p=0.01$, morphine vs aCSF, $p<0.001)$. However, the number of CREB-positive neurons was significantly higher in the drug reward group than in the food reward group (crisps vs morphine, $p<0.001$ ). This pattern cannot be explained by direct pharmacological effects of morphine because it was absent in the yoked control (morphine vs yoked, $p<0.001$ ). In the ventral striatum (NAc), both rewards induced CREB phosphorylation, but a higher level of pCREB expression was observed in the morphine group (reward effect, $F_{(3,25)}=9.00, p=0.001$; post hoc crisps vs aCSF, $p<0.01$; morphine vs aCSF, $p<0.001$; morphine vs yoked, $p<0.01$ ).

In contrast to the STR, no significant change in CREB phosphorylation was observed in the CA1 field of the hippocampus during cue-guided learning in the food reward group. However, the drug reward group displayed more pCREB-positive neurons in this structure than food rewarded mice (reward effect, $F_{(3,25)}=$ $12.92, p<0.001$; post hoc morphine vs aCSF, $p<0.01$; morphine vs crisps, $p<0.001)$. Because the same pattern was present also in yoked controls, this increase is likely to not be learning dependent but may be related instead to the effects of morphine itself (yoked vs aCSF, $p=0.001$; yoked vs morphine, $p>0.05$ ).
Interestingly, an opposite pattern was observed within the CA3 field of the dorsal hippocampus compared with CA1. Whereas food-rewarded mice showed a significant increase in the number of pCREB-positive neurons, drug reinforcement strongly decreased pCREB expression (reward effect, $F_{(3,25)}=33.55, p<$ 0.001; post hoc crisps vs aCSF, $p<0.001$; morphine vs aCSF, $p<0.001$; crisps vs morphine, $p<0.001$; morphine vs yoked, $p=0.012)$. No change in PCREB expression was observed within the PFC.

\section{Brain regional expression of pCREB: spatial discrimination task}

After the acquisition of the Y-maze spatial task, modifications of the pattern of CREB phosphorylation appeared throughout the brain as a function of the type of reward given to mice (Fig. 6, 7). First, in the CA1 field of the hippocampus, the spatial protocol induced a significant increase in CREB phosphorylation when mice were reinforced with crisps compared with other groups that presented a basal pCREB level (reward effect, $F_{(4,28)}=4.20, p=0.008$; post hoc crisps vs aCSF, $p<0.001$; crisps vs morphine, $p=0.01$; crisps vs morphine-crisps, $p=0.005$; morphine vs aCSF, $p>0.05$; morphine-crisps vs aCSF, $p>0.05$; yoked vs aCSF, $p>0.05)$. In the CA3, the crisps group presented a high pCREB expression that, in contrast, was inhibited in other groups (reward effect, $F_{(4,28)}=7.55, p<0.001$; post hoc crisps vs aCSF, $p=0.007$; crisps vs morphine, $p<0.001$; crisps vs morphinecrisps, $p=0.001$; crisps vs yoked, $p=0.01$; morphine vs aCSF, $p>0.05$; morphine-crisps vs aCSF, $p>0.05$; yoked vs aCSF, $p>$ $0.05)$. In the PFC, the crisps group exhibited a large increase of CREB phosphorylation that was inhibited by morphine (reward effect, $F_{(4,28)}=8.52, p=0.001$; post hoc crisps vs aCSF, $p<$ 0.001 ; crisps vs morphine, $p<0.001$; crisps vs morphine-crisps, $p<0.001$; crisps vs yoked, $p=0.001$; morphine vs aCSF, $p>$ 0.05 ; morphine-crisps vs aCSF, $p>0.05$; yoked vs aCSF, $p>$ $0.05)$. In the STR, the spatial protocol did not induce any CREB phosphorylation in the crisps group. However, morphine and morphine-crisps animals presented a slight increase in PCREB expression compared with crisps and yoked mice (reward effect, $F_{(4,28)}=$ $4.02, p=0.01$; post hoc morphine vs crisps, $p=0.02$; morphine vs yoked, $p=0.005$; morphine-crisps vs crisps, $p=0.01$; morphinecrisps vs yoked, $p=0.003)$. Finally, in the NAc, morphine induced a high level of CREB phosphorylation in behaving animals compared with other groups (reward effect, $F_{(4,28)}=3.12, p=0.03$; post hoc morphine vs aCSF, $p=0.004$; morphine-crisps vs aCSF, $p=0.005$; crisps vs aCSF, $p=0.07$; morphine vs yoked, $p>0.05$; morphinecrisps vs yoked, $p>0.05$ ). To summarize these data, percentage changes in PCREB immunoreactivity observed in each brain structure were plotted on four-axis radar charts (Fig. 8). The figure highlights a clear-cut antagonism between hippocampal and striatal memory systems.

\section{Brain regional expression of c-Fos after spatial learning}

As we observed previously, spatial learning was impaired when intra-VTA morphine was given as a reward (Fig. 9), whereas crisps-reinforced animals quickly learned the spatial discrimina- 


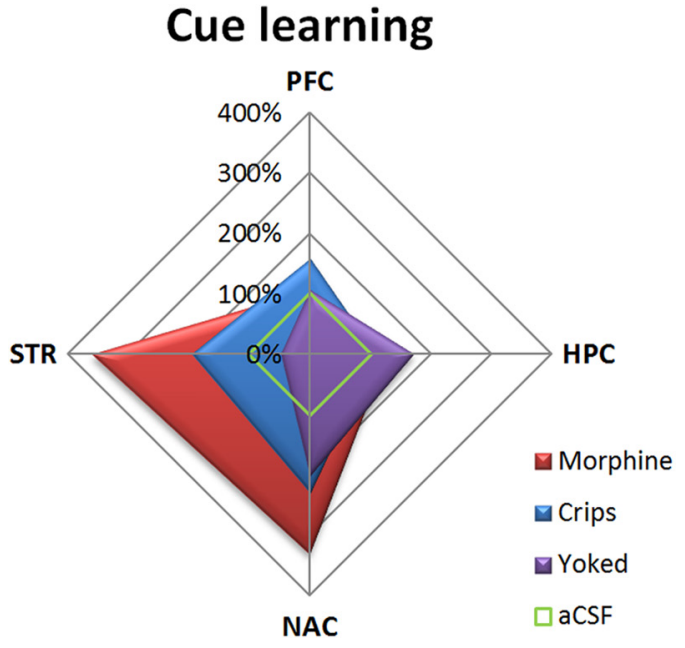

\section{Spatial learning}

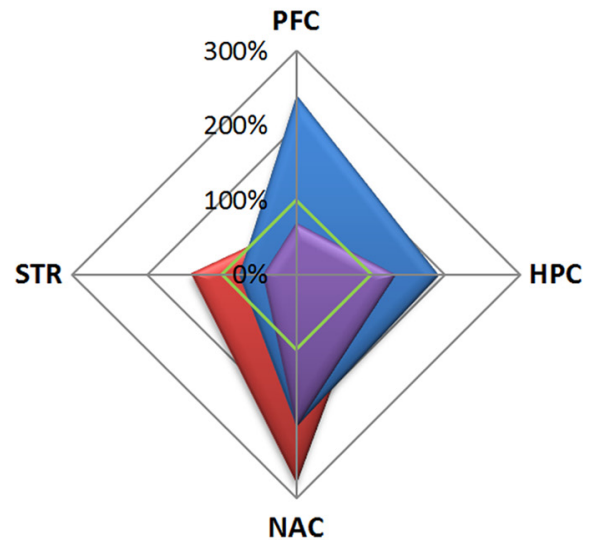

Figure 8. Summary of $p C R E B$ immunostaining changes relative to aCSF animals (100\%). Food-reinforced animals exhibited a task-dependent pattern of expression, with a strong activation of hippocampus (HPC) and PFC after spatial learning, whereas the cue-guided task elicited pCREB within the NAc and dorsal STR. This dissociation pattern was absent in drug-reinforced mice, which displayed greater activations of both ventral and dorsal STR after either the spatial or the cue-guided task.

tion task (reward effect, $F_{(2,16)}=26.40, p<0.001$; session effect, $F_{(9,144)}=2.37, p=0.01$; reward $\times$ session interaction, $F_{(18,144)}=$ 2.87, $p=0.002$; post hoc aCSF vs crisps, $p<0.001$; aCSF vs morphine, $p>0.05$; morphine vs crisps, $p<0.001$ ). Both learning and rewards modulate c-Fos expression (Fig. 9). Morphine elicited high c-Fos levels in the NAc (reward effect, $F_{(3,22)}=9.97$, $p=0.002$; post hoc morphine vs aCSF, $p<0.001$; morphine vs crisps, $p<0.001$; yoked vs aCSF, $p=0.032$; yoked vs crisps, $p=$ 0.015 ; crisps vs aCSF, $p=0.05$; morphine vs yoked, $p>0.05)$ and in the dorsal STR (reward effect, $F_{(3,22)}=3.48, p=0.03$; post hoc morphine vs aCSF, $p<0.01$; morphine vs crisps, $p>0.05$; yoked vs aCSF, $p>0.05$; yoked vs crisps, $p>0.05$; crisps vs aCSF, $p>$ 0.05 ; morphine vs yoked, $p>0.05$ ). In the hippocampus, as observed previously for pCREB, the spatial protocol elicited strong c-Fos expression in crisps-reinforced animals compared with morphine-injected mice and aCSF controls. In the CA1 subfield of the hippocampus, the number of c-Fos-positive cells was higher in crisps-rewarded animals than in other groups (reward effect, $F_{(3,22)}=6.29, p=0.003$; post hoc crisps vs aCSF, $p=0.001$; crisps vs morphine, $p=0.005$; crisps vs yoked, $p<0.001$; morphine vs aCSF, $p>0.05$; yoked vs aCSF, $p>0.05$; morphine vs yoked, $p>0.05)$. Similarly, Fos expression in the CA3 subfield of the hippocampus was increased in crisps-rewarded animals compared with other groups ( reward effect, $F_{(3,22)}=5.69, p=0.004$; post hoc crisps vs aCSF, $p=0.001$; crisps vs morphine, $p=0.003$; crisps vs yoked, $p=0.002$; morphine vs aCSF, $p>0.05$; yoked vs aCSF, $p>0.05$; morphine vs yoked, $p>0.05)$. Finally, the type of reward did not induce significant changes in c-Fos expression within PFC after day 10 (reward effect, $F_{(3,22)}=2.59, p>0.05$ ).

\section{$\mathrm{Rp}$-cAMPS pretreatment reverses the drug-induced spatial deficit}

Pretraining injections of Rp-cAMPS into the dorsal STR completely reversed the morphine-induced spatial deficit, restoring the learning performance in drug-rewarded mice to the level of food-rewarded animals (Fig. 10B) (treatment effect, $F_{(1,10)}=$ 33.86, $p=0.001$; session effect, $F_{(9,90)}=3.16, p=0.002$; treatment $X$ session interaction:, $\left.F_{(9,90)}=3.59, p=0.001\right)$. Day-byday analysis revealed that pretreated animals performed the task with better accuracy than aCSF-treated controls from day 3 to day 10 (all $p<0.05$ ). Both groups completed trials faster over the course of sessions (Fig. 10C), and the treatment did not alter this velocity parameter (treatment effect, $F_{(1,10)}=0.87$, NS; session effect, $F_{(9,90)}=5.79, p<0.001$; treatment $\times$ session interaction, $\left.F_{(9,90)}=0.27, \mathrm{NS}\right)$. The Rp-cAMPS treatment also fully restored CREB phosphorylation (Fig. 10D) in the CA1 subfield of the hippocampus (treatment effect, $F_{(1,10)}=16.20, p=0.002$ ), in the CA3 subfield (treatment effect, $F_{(1,10)}=21.59, p=0.001$ ), and in the PFC (treatment effect, $F_{(1,10)}=34.61, p=0.001$ ), whereas CREB phosphorylation within the NAc was not significantly altered (treatment effect, $F_{(1,10)}=0.33$, NS).

\section{Discussion}

This study was aimed at comparing the impact of food- and drug-induced activation of the reward system on different forms of memory. One of our main observations is that drug reward impaired the acquisition of a discrimination task only when a spatial strategy was required to learn the task, whereas acquisition of its cue-guided version was fully preserved. In contrast, foodreinforced subjects exhibited similar learning performance in both versions of the task. Consistent with behavioral results, a clear-cut dissociation pattern of pCREB was observed in mice reinforced with food. After spatial learning, these subjects exhibited high pCREB levels within the hippocampus (CA1 and CA3) but no change in the dorsal STR. Conversely, cued learning elicited significant pCREB expression within the dorsal STR but decreased the number of pCREB-positive CA1 hippocampal neurons compared with drug-reinforced subjects. c-Fos labeling revealed a very similar pattern, suggesting that regional brain CREB activity was followed by downstream immediate early genes involved in learning-evoked plasticity signaling, as described with extracellular signal-regulated kinases (Girault et al., 2007).

This dissociated pattern is remarkably consistent with two studies showing that (1) rats trained in a cross maze exhibited pCREB and c-Fos immunoreactivity in the hippocampus and the dorsal STR depending on whether they learned the task using a place or response strategy, respectively (Colombo et al., 2003), and (2) excitotoxic lesion or transgenic inhibition of dorsostriatal CREB impaired cued learning but enhanced spatial function, whereas hippocampal lesions had the opposite effect (Lee et al., 2008). These results support the view of a functional antagonism between hippocampus and striatum depending on the nature of the task (Poldrack and Packard, 2003; Daw et al., 2005). This double dissociation pattern was blunted in drug-reinforced mice, which exhibited more pCREB-positive ventral striatal neurons 

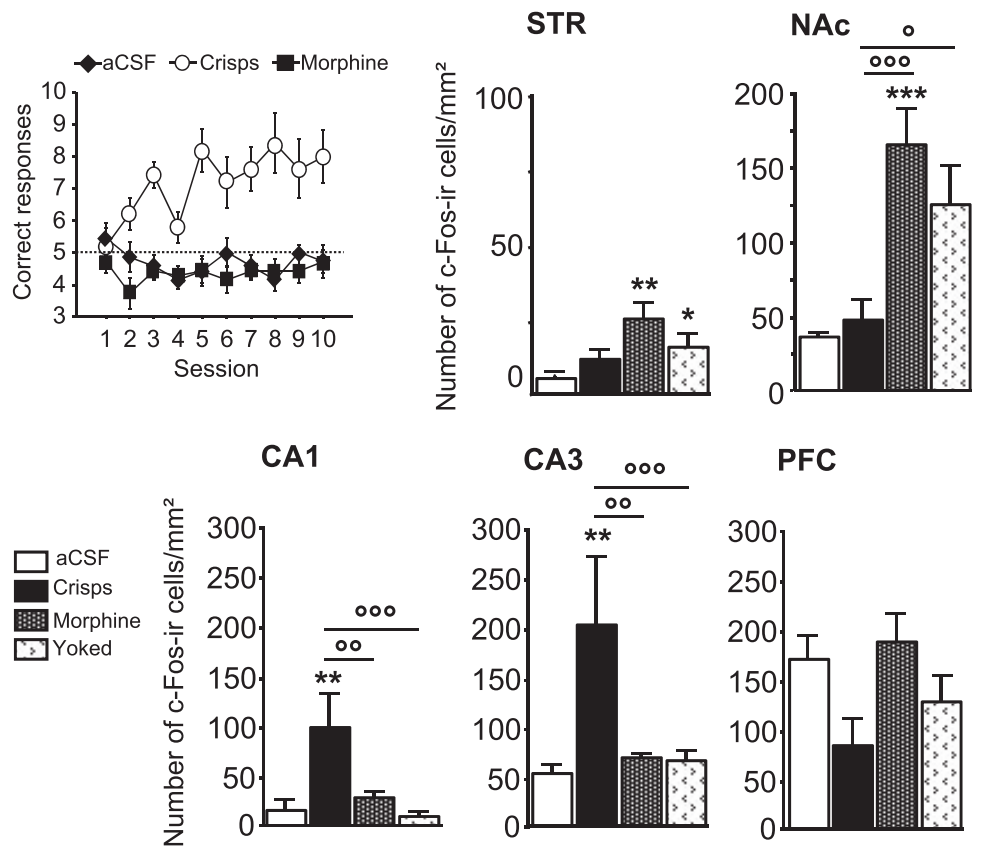

Figure 9. Learning-induced brain regional changes in c-Fos immunoreactivity after 10 training days in the spatial version of the Y-maze arm discrimination task. Top left graph shows learning performances in subjects used for the c-Fos study. Measures are expressed as mean \pm SEM number of c-Fos immunoreactive (c-Fos-ir) cells per square millimeter in the STR, NAC, CA1, CA3, and PFC. Comparison with aCSF group: ${ }^{* *} p<0.01,{ }^{* * *} p<0.001$; other comparisons: ${ }^{\circ} p<0.05,{ }^{\circ 0} p<0.01,{ }^{\circ 00} p<0.001$.

neously were impaired similarly to subjects reinforced only with intra-VTA morphine, the absence of the consummatory phase cannot account for the druginduced spatial deficit.

Repeated exposure to opiates typically decreases CREB phosphorylation in the NAc, hippocampus, and locus ceruleus (Guitart et al., 1992; Widnell et al., 1996; Yang and $\mathrm{Pu}, 2009)$. However, morphineinduced conditioned place preference (CPP) induces CREB phosphorylation in hippocampus, NAc, and/or PFC depending on memory phases (Olson et al., 2005; Zhou and Zhu, 2006; Morón et al., 2010). CREB hypomorphs mice do not exhibit morphine CPP (Walters and Blendy, 2001). Viral-mediated or transgenic inhibition of CREB activity that targets striatal regions facilitates cocaine and morphine CPP and enhances locomotor sensitization to cocaine and the rewarding impact of brain stimulation (Carlezon et al., 1998, 2005; Barrot et al., 2002; Dinieri et al., 2009; Fasano et al., 2009; Sanchis-Segura et al., 2009). Together with these data, our results suggest that CREB phosphorylation is related not only to direct pharma-

even when trained with the spatial protocol. In addition, the spatial deficit was tagged by drastic decreases in pCREB expression within the dorsal hippocampus and the PFC compared with mice reinforced with crisps. Extensive evidence supports the idea that CREB plays an essential role in memory formation. Inhibition of CREB phosphorylation within the hippocampus (Bourtchuladze et al., 1994) or the PFC (Hotte et al., 2006) impairs the induction of long-term potentiation within these brain regions, leading to a significant deficit in spatial tasks (Laroche et al., 2000; Conejo et al., 2010). Therefore, the decrease in hippocampal CREB activity observed here likely accounts for the spatial learning deficit in drug-reinforced mice.

In sharp contrast to the spatial learning condition, drugreinforced subjects quickly acquired the cue-guided version of the discrimination task, during which they had to associate a salient cue with the delivery of the reward. Optimal cued learning performance correlated with large increases in $\mathrm{PCREB}$ expression within the NAc and the dorsal STR in both food- and drugreinforced mice. These results are consistent with the previously reported disruption of striatal plasticity and cued learning through expression of a dominant-negative mutant form of CREB in the dorsal STR (Pittenger et al., 2006; Lee et al., 2008) and with the view that action-outcome instrumental learning relies on the dorsal STR (Yin and Knowlton, 2006; Valentin et al., 2007; Balleine et al., 2009). The rapid acquisition of the cued Y-maze discrimination task also demonstrated that intra-VTA morphine injections serve as an efficient reinforcer. Indeed, unsensed rewards can elicit strong rewarding effects despite the fact that they bypass sensory integration (Wise, 2002). However, food-reinforced but not drug-reinforced mice displayed a complex motor procedure when reaching the correct arm: they take the crisp in their hands, chew it, and then swallow it. It is possible that absence of this consummatory or response sequence (Skinner, 1934) in drug-reinforced subjects weakens spatial memory. Because control animals receiving both types of rewards simulta- cological effects of morphine but also to the form of memory involved. This view is supported by results of the yoked control group, demonstrating that, although morphine itself was sufficient to elicit CREB activity in the hippocampus and NAc, spatial and cued learning were associated with higher levels of pCREB expression, respectively, in the hippocampus and striatum. Our observations are consistent with a recent report showing that CREB phosphorylation is related to the sensitized response to morphine-induced conditioning in brain areas involved in memory consolidation (Morón et al. 2010).

Although our behavioral and CREB imaging results are consistent with the framework of a functional antagonism between hippocampus and striatum, it remained to be demonstrated that drug-induced hyperactivity of the STR is responsible for the spatial learning deficit. We thus tested additional groups of drugreinforced mice receiving bilateral infusions of either aCSF or the PKA inhibitor Rp-cAMPS into the dorsal STR, which were compared with food-reinforced subjects as positive controls. The RpcAMPS pretreatment completely prevented the drug-induced spatial deficit and restored hippocampal and PFC pCREB phosphorylation to the level of food-reinforced subjects. Previous studies investigating the role of PKA in drug-induced conditioning or appetitive learning have provided converging evidence that intra-striatal (NAc) administration of PKA activators facilitate whereas inhibitors reduce S-R learning and drug-motivated behaviors (Kelley, 2004; Arnsten et al., 2005; Lynch and Taylor, 2005). Repeated administration of PKA inhibitors into the NAc (core) impairs food-reinforced instrumental learning (Baldwin et al., 2002). However, overactivation of PKA also impairs this form of learning. Therefore, facilitating/disrupting effects of PKA modulators may depend on their ability to maintain an optimum level of PKA activity for the ongoing task. The presently reported recovery of both spatial learning and hippocampal CREB activity through inhibition of striatal PKA provides additional evidence 
that reduction of the drug-induced striatal PKA/CREB hyperactivity allowed normal hippocampal/PFC function.

The complete circuitry mediating the deleterious effect of striatal overactivation on the hippocampal function has yet to be fully understood. VTA DA neurons project to the NAc, which in turn send back projections to the VTA/SN area, which projects more dorsally to the striatum: this ventrodorsal striatal loop is implicated in instrumental behaviors (Haber et al., 2000; Belin and Everitt, 2008). Our results suggest that recruitment of ventrodorsal striatal loops after repeated druginduced activation of the reward system could modulate the hippocampus/striatum pCREB ratio, prompting S-R learning to the detriment of spatial function. This hypothetical mechanism fits well with the view that transition to addiction implicates aberrant S-R learning, which progressively leads to loss of voluntary control (Everitt and Robbins, 2005; Belin et al., 2009). Other neural mechanisms may be involved. High concentration of DA stimulates $\mathrm{D}_{2}-\mathrm{DA}$ receptors throughout the PFC, thereby decreasing NMDAdependent currents, disrupting LTP induction and CREB phosphorylation (Zheng et al., 1999). Accordingly, raising DA levels or activating PKA within the PFC impairs working memory (Goldman-Rakic et al., 2000). DA-dependent alteration of prefrontohippocampal circuits involved in the consolidation of events linked to the reward could thus account for the spatial deficit in drug-reinforced subjects. Interestingly, chronic intake of drugs of abuse induce a hypofrontality-like syndrome in animals (Jentsch and Taylor, 1999; Homayoun and Moghaddam, 2006; Sun and Rebec, 2006) and addicted humans (Goldstein and Volkow, 2002; Kalivas et al., 2005; Goldstein et al., 2007). Morphine-induced increases in DA release within other brain regions may have occurred: activation of the basolateral amygdala elicited by emotionally charged events impairs hippocampus-dependent learning and synaptic plasticity (Akirav and Richter-Levin, 1999; Kim and Diamond, 2002; Layton and Krikorian, 2002). The present disruptive effect of drug reward on spatial learning shows striking similarities with the effects of stress on memory and hippocampal synaptic plasticity (Kim and Diamond, 2002; Sandi and Pinelo-Nava, 2007; Schwabe et al., 2007, 2010b).

In conclusion, our present observations provide strong evidence that drug-induced activation of the reward system disrupts spatial learning while supporting a cue-guided version of the task. Food-reinforced subjects exhibited efficient spatial and cued learning related, respectively, to CREB activity in the hippocam-
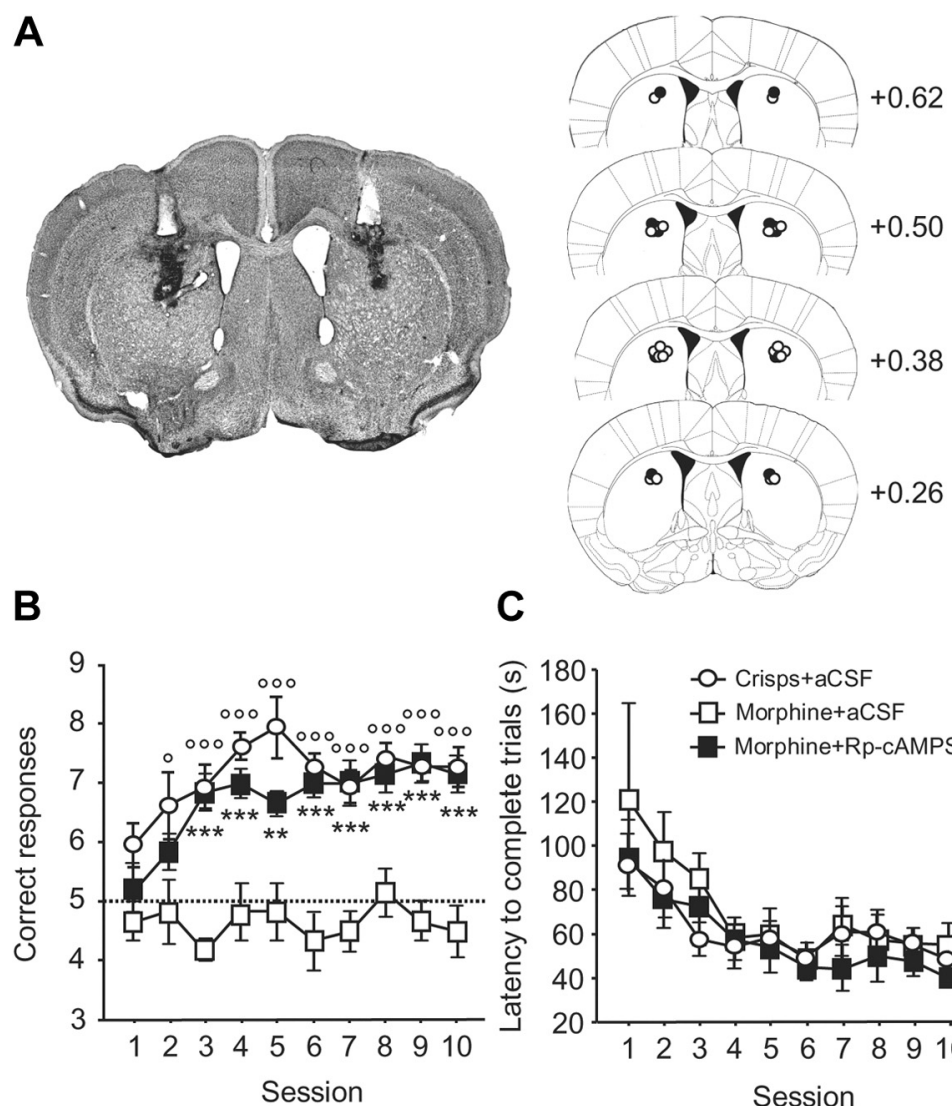

\section{C}
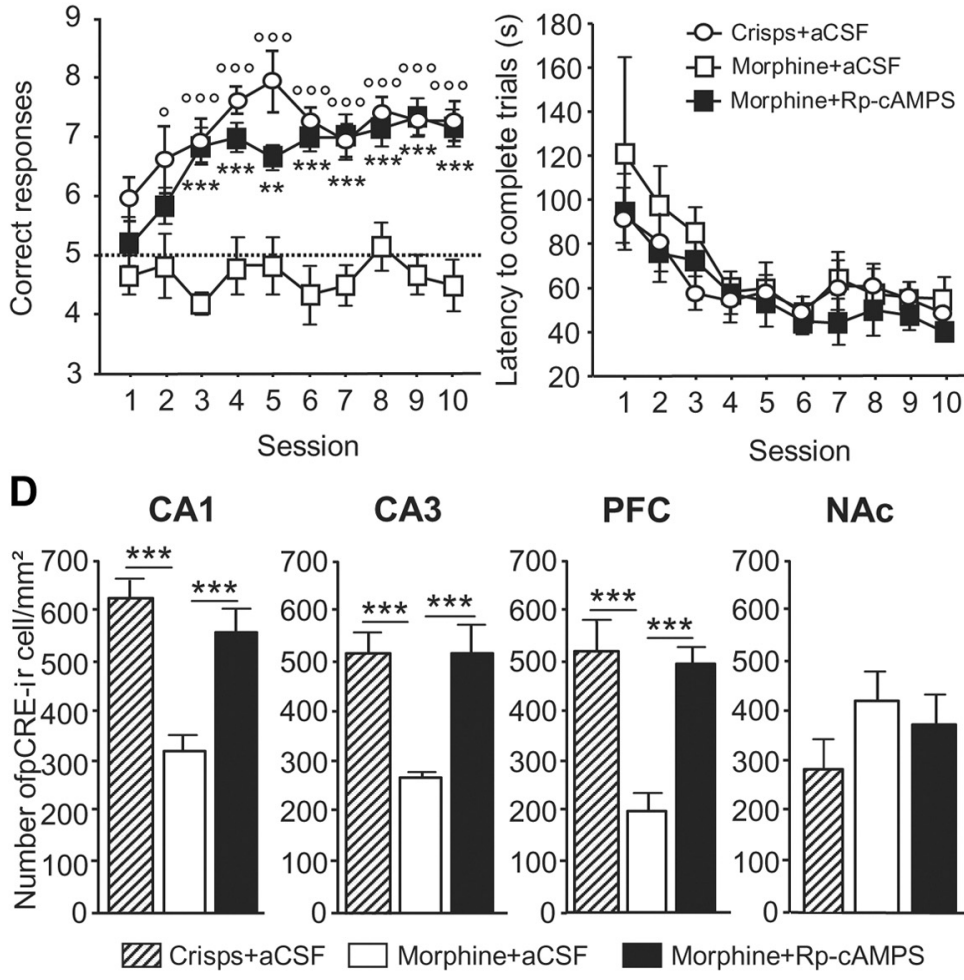

Figure 10. Acquisition of the spatial version of the $Y$-maze arm discrimination task in morphine-rewarded animals infused with either Rp-cAMPS or aCSF into the dorsal STR before each training session. $\boldsymbol{A}$, Schematic representation of injection sites in the dorsal STR. Left, Wide representative microphotographic view of injection sites, showing tracks of guide cannulas (white track) and injection cannulas (black track). Right, Histological control of all stereotaxically implanted mice. Dots show locations of the tip of injection cannulas (black dots, Rp-CAMPS injection; white dots, aCSF injection) (stereotaxic coordinates: anteroposterior, $0.62 \mathrm{~mm}$ to bregma; lateral, $\pm 1.9 \mathrm{~mm}$; ventral, $1.5 \mathrm{~mm}$ ). $\boldsymbol{B}$, Morphine-rewarded mice pretreated with Rp-cAMPS exhibited more correct responses per session compared with aCSF-injected animals ( $p<0.001$; morphine + Rp-cAMPS vs morphine + aCSF: ${ }^{* *} p<$ $\left.0.01{ }^{* * *} p<0.001\right)$. As expected, crisps-rewarded animals made more correct responses than morphine-rewarded mice when both groups were preinfused with aCSF into the dorsal STR ( $p<0.001$; $\operatorname{crisps}+$ aCSF vs morphine + aCSF: ${ }^{\circ} p<0.05,{ }^{\circ 00} p<$ 0.001).C, The treatment did not alter locomotion, as assessed by the time to complete trials, which decreased in all groups over the course of training sessions $(p<0.001)$. $D$, Region-specific pattern of $p C R E B$ expression after acquisition of the spatial discrimination task. Measures are expressed as mean \pm SEM number of $p C R E B$-immunoreactive ( $p C R E B$-ir) cells per square millimeter in the CA1, CA3, PFC, and NAC (comparisons with morphine-aCSF-treated group: ${ }^{* * *} p<0.001$ ).

pus/PFC and the dorsal STR. This double dissociation pattern was blunted in drug-reinforced subjects. Inhibition of the striatal PKA/CREB pathway fully restored normal spatial learning and hippocampal/PFC CREB activity in these subjects, suggesting that hyperactivity of the striatum may be responsible for the spatial deficit. Given the possible role of this cognitive impairment in 
the transition to addictive behaviors, additional work should be aimed at understanding the neural bases of the relationship between well-documented habit-forming actions of drugs of abuse and the unexpected declarative deficit reported here.

\section{References}

Akirav I, Richter-Levin G (1999) Biphasic modulation of hippocampal plasticity by behavioral stress and basolateral amygdala stimulation in the rat. J Neurosci 19:10530-10535.

Arnsten AF, Ramos BP, Birnbaum SG, Taylor JR (2005) Protein kinase A as a therapeutic target for memory disorders: rationale and challenges. Trends Mol Med 11:121-128.

Baldwin AE, Sadeghian K, Holahan MR, Kelley AE (2002) Appetitive instrumental learning is impaired by inhibition of cAMP-dependent protein kinase within the nucleus accumbens. Neurobiol Learn Mem 77:44-62.

Balleine BW, Liljeholm M, Ostlund SB (2009) The integrative function of the basal ganglia in instrumental conditioning. Behav Brain Res 199:43-52.

Barrot M, Olivier JD, Perrotti LI, DiLeone RJ, Berton O, Eisch AJ, Impey S, Storm DR, Neve RL, Yin JC, Zachariou V, Nestler EJ (2002) CREB activity in the nucleus accumbens shell controls gating of behavioral responses to emotional stimuli. Proc Natl Acad Sci U S A 99:11435-11440.

Belin D, Everitt BJ (2008) Cocaine seeking habits depend upon dopaminedependent serial connectivity linking the ventral with the dorsal striatum. Neuron 57:432-441.

Belin D, Jonkman S, Dickinson A, Robbins TW, Everitt BJ (2009) Parallel and interactive learning processes within the basal ganglia: relevance for the understanding of addiction. Behav Brain Res 199:89-102.

Bourtchuladze R, Frenguelli B, Blendy J, Cioffi D, Schutz G, Silva AJ (1994) Deficient long-term memory in mice with a targeted mutation of the cAMP-responsive element-binding protein. Cell 79:59-68.

Bozarth MA (1987) Neuroanatomical boundaries of the reward-relevant opiate-receptor field in the ventral tegmental area as mapped by the conditioned place preference method in rats. Brain Res 414:77-84.

Bromberg-Martin ES, Matsumoto M, Hikosaka O (2010) Dopamine in motivational control: rewarding, aversive, and alerting. Neuron 68:815-834.

Carlezon WA Jr, Thome J, Olson VG, Lane-Ladd SB, Brodkin ES, Hiroi N, Duman RS, Neve RL, Nestler EJ (1998) Regulation of cocaine reward by CREB. Science 282:2272-2275.

Carlezon WA Jr, Duman RS, Nestler EJ (2005) The many faces of CREB. Trends Neurosci 28:436-445.

Colombo PJ, Brightwell JJ, Countryman RA (2003) Cognitive strategyspecific increases in phosphorylated cAMP response element-binding protein and c-Fos in the hippocampus and dorsal striatum. J Neurosci 23:3547-3554.

Conejo NM, González-Pardo H, Gonzalez-Lima F, Arias JL (2010) Spatial learning of the water maze: progression of brain circuits mapped with cytochrome oxidase histochemistry. Neurobiol Learn Mem 93:362-371.

David V, Durkin TP, Cazala P (2002) Differential effects of the dopamine D2/D3 receptor antagonist sulpiride on self-administration of morphine into the ventral tegmental area or the nucleus accumbens. Psychopharmacology (Berl) 160:307-317.

David V, Matifas A, Gavello-Baudy S, Decorte L, Kieffer BL, Cazala P (2008) Brain regional Fos expression elicited by the activation of mu- but not delta-opioid receptors of the ventral tegmental area: evidence for an implication of the ventral thalamus in opiate reward. Neuropsychopharmacology 33:1746-1759.

Daw ND, Niv Y, Dayan P (2005) Uncertainty-based competition between prefrontal and dorsolateral striatal systems for behavioral control. Nat Neurosci 8:1704-1711.

Dickinson A, Balleine B (1990) Motivational control of instrumental performance following a shift from thirst to hunger. Q J Exp Psychol B 42:413-431.

Dinieri JA, Nemeth CL, Parsegian A, Carle T, Gurevich VV, Gurevich E, Neve RL, Nestler EJ, Carlezon WA Jr (2009) Altered sensitivity to rewarding and aversive drugs in mice with inducible disruption of cAMP response element-binding protein function within the nucleus accumbens. J Neurosci 29:1855-1859.

Dudman JT, Eaton ME, Rajadhyaksha A, Macías W, Taher M, Barczak A, Kameyama K, Huganir R, Konradi C (2003) Dopamine D1 receptors mediate CREB phosphorylation via phosphorylation of the NMDA receptor at Ser897-NR1. J Neurochem 87:922-934.
Eichenbaum H, Stewart C, Morris RG (1990) Hippocampal representation in place learning. J Neurosci 10:3531-3542.

Everitt BJ, Robbins TW (2005) Neural systems of reinforcement for drug addiction: from actions to habits to compulsion. Nat Neurosci 8:1481-1489.

Fallon JH, Riley JN, Moore RY (1978) Substantia nigra dopamine neurons: separate populations project to neostriatum and allocortex. Neurosci Lett $7: 157-162$.

Fasano S, Pittenger C, Brambilla R (2009) Inhibition of CREB activity in the dorsal portion of the striatum potentiates behavioral responses to drugs of abuse. Front Behav Neurosci 3:29.

Gasbarri A, Sulli A, Innocenzi R, Pacitti C, Brioni JD (1996) Spatial memory impairment induced by lesion of the mesohippocampal dopaminergic system in the rat. Neuroscience 74:1037-1044.

Girault JA, Valjent E, Caboche J, Hervé D (2007) ERK2: a logical AND gate critical for drug-induced plasticity? Curr Opin Pharmacol 7:77-85.

Goldman-Rakic PS, Muly EC 3rd, Williams GV (2000) D(1) receptors in prefrontal cells and circuits. Brain Res Brain Res Rev 31:295-301.

Goldstein RZ, Volkow ND (2002) Drug addiction and its underlying neurobiological basis: neuroimaging evidence for the involvement of the frontal cortex. Am J Psychiatry 159:1642-1652.

Goldstein RZ, Tomasi D, Rajaram S, Cottone LA, Zhang L, Maloney T, Telang F, Alia-Klein N, Volkow ND (2007) Role of the anterior cingulate and medial orbitofrontal cortex in processing drug cues in cocaine addiction. Neuroscience 144:1153-1159.

Guitart X, Thompson MA, Mirante CK, Greenberg ME, Nestler EJ (1992) Regulation of cyclic AMP response element-binding protein (CREB) phosphorylation by acute and chronic morphine in the rat locus coeruleus. J Neurochem 58:1168-1171.

Guzowski JF, McGaugh JL (1997) Antisense oligodeoxynucleotidemediated disruption of hippocampal cAMP response element binding protein levels impairs consolidation of memory for water maze training. Proc Natl Acad Sci U S A 94:2693-2698.

Haber SN, Fudge JL, McFarland NR (2000) Striatonigrostriatal pathways in primates form an ascending spiral from the shell to the dorsolateral striatum. J Neurosci 20:2369-2382.

Homayoun H, Moghaddam B (2006) Progression of cellular adaptations in medial prefrontal and orbitofrontal cortex in response to repeated amphetamine. J Neurosci 26:8025-8039.

Hotte M, Thuault S, Lachaise F, Dineley KT, Hemmings HC, Nairn AC, Jay TM (2006) D1 receptor modulation of memory retrieval performance is associated with changes in PCREB and pDARPP-32 in rat prefrontal cortex. Behav Brain Res 171:127-133.

Hyman SE, Malenka RC, Nestler EJ (2006) Neural mechanisms of addiction: the role of reward-related learning and memory. Annu Rev Neurosci 29:565-598.

Ikemoto S (2007) Dopamine reward circuitry: two projection systems from the ventral midbrain to the nucleus accumbens-olfactory tubercle complex. Brain Res Rev 56:27-78.

Jentsch JD, Taylor JR (1999) Impulsivity resulting from frontostriatal dysfunction in drug abuse: implications for the control of behavior by reward-related stimuli. Psychopharmacology (Berl) 146:373-390.

Johnson SW, North RA (1992) Opioids excite dopamine neurons by hyperpolarization of local interneurons. J Neurosci 12:483-488.

Josselyn SA, Shi C, Carlezon WA Jr, Neve RL, Nestler EJ, Davis M (2001) Long-term memory is facilitated by cAMP response element-binding protein overexpression in the amygdala. J Neurosci 21:2404-2412.

Kalivas PW, Volkow N, Seamans J (2005) Unmanageable motivation in addiction: a pathology in prefrontal-accumbens glutamate transmission. Neuron 45:647-650.

Kelley AE (2004) Memory and addiction: shared neural circuitry and molecular mechanisms. Neuron 44:161-179.

Kim JJ, Diamond DM (2002) The stressed hippocampus, synaptic plasticity and lost memories. Nat Rev Neurosci 3:453-462.

Kim JJ, Lee HJ, Han JS, Packard MG (2001) Amygdala is critical for stressinduced modulation of hippocampal long-term potentiation and learning. J Neurosci 21:5222-5228.

Lammel S, Hetzel A, Häckel O, Jones I, Liss B, Roeper J (2008) Unique properties of mesoprefrontal neurons within a dual mesocorticolimbic dopamine system. Neuron 57:760-773.

Laroche S, Davis S, Jay TM (2000) Plasticity at hippocampal to prefrontal 
cortex synapses: dual roles in working memory and consolidation. Hippocampus 10:438-446.

Layton B, Krikorian R (2002) Memory mechanisms in posttraumatic stress disorder. J Neuropsychiatry Clin Neurosci 14:254-261.

Lee AS, Duman RS, Pittenger C (2008) A double dissociation revealing bidirectional competition between striatum and hippocampus during learning. Proc Natl Acad Sci U S A 105:17163-17168.

Lynch WJ, Taylor JR (2005) Persistent changes in motivation to selfadminister cocaine following modulation of cyclic AMP-dependent protein kinase A (PKA) activity in the nucleus accumbens. Eur J Neurosci 22:1214-1220.

Martel G, Millard A, Jaffard R, Guillou JL (2006) Stimulation of hippocampal adenylyl cyclase activity dissociates memory consolidation processes for response and place learning. Learn Mem 13:342-348.

Martel G, Blanchard J, Mons N, Gastambide F, Micheau J, Guillou JL (2007) Dynamic interplays between memory systems depend on practice: the hippocampus is not always the first to provide solution. Neuroscience 150:743-753.

Matthews RT, German DC (1984) Electrophysiological evidence for excitation of rat ventral tegmental area dopamine neurons by morphine. Neuroscience 11:617-625.

McBride WJ, Murphy JM, Ikemoto S (1999) Localization of brain reinforcement mechanisms: intracranial self-administration and intracranial place-conditioning studies. Behav Brain Res 101:129-152.

McDonald RJ, White NM (1994) Parallel information processing in the water maze: evidence for independent memory systems involving dorsal striatum and hippocampus. Behav Neural Biol 61:260-270.

McDonald RJ, Devan BD, Hong NS (2004) Multiple memory systems: the power of interactions. Neurobiol Learn Mem 82:333-346.

Montague PR, Dayan P, Sejnowski TJ (1996) A framework for mesencephalic dopamine systems based on predictive Hebbian learning. J Neurosci 16:1936-1947.

Morón JA, Gullapalli S, Taylor C, Gupta A, Gomes I, Devi LA (2010) Modulation of opiate-related signaling molecules in morphine-dependent conditioned behavior: conditioned place preference to morphine induces CREB phosphorylation. Neuropsychopharmacology 35:955-966.

Nugent FS, Penick EC, Kauer JA (2007) Opioids block long-term potentiation of inhibitory synapses. Nature 446:1086-1090.

Oades RD, Halliday GM (1987) Ventral tegmental (A10) system: neurobiology. 1. Anatomy and connectivity. Brain Res 434:117-165.

Olson VG, Zabetian CP, Bolanos CA, Edwards S, Barrot M, Eisch AJ, Hughes T, Self DW, Neve RL, Nestler EJ (2005) Regulation of drug reward by cAMP response element-binding protein: evidence for two functionally distinct subregions of the ventral tegmental area. J Neurosci 25:55535562.

Packard MG (1999) Glutamate infused posttraining into the hippocampus or caudate-putamen differentially strengthens place and response learning. Proc Natl Acad Sci U S A 96:12881-12886.

Paxinos G, Franklin K (2001) The mouse brain in stereotaxic coordinates, Ed 2. San Diego: Academic.

Phillips AG, LePiane FG (1980) Reinforcing effects of morphine microinjection into the ventral tegmental area. Pharmacol Biochem Behav 12:965-968.

Pittenger C, Huang YY, Paletzki RF, Bourtchouladze R, Scanlin H, Vronskaya S, Kandel ER (2002) Reversible inhibition of CREB/ATF transcription factors in region CA1 of the dorsal hippocampus disrupts hippocampusdependent spatial memory. Neuron 34:447-462.

Pittenger C, Fasano S, Mazzocchi-Jones D, Dunnett SB, Kandel ER, Brambilla $R$ (2006) Impaired bidirectional synaptic plasticity and procedural memory formation in striatum-specific cAMP response element-binding protein-deficient mice. J Neurosci 26:2808-2813.

Poldrack RA, Packard MG (2003) Competition among multiple memory systems: converging evidence from animal and human brain studies. Neuropsychologia 41:245-251.

Porte Y, Buhot MC, Mons NE (2008) Spatial memory in the Morris water maze and activation of cyclic AMP response element-binding (CREB) protein within the mouse hippocampus. Learn Mem 15:885-894.

Ramos BP, Birnbaum SG, Lindenmayer I, Newton SS, Duman RS, Arnsten AF (2003) Dysregulation of protein kinase a signaling in the aged prefrontal cortex: new strategy for treating age-related cognitive decline. Neuron 40:835-845.

Reading PJ, Dunnett SB, Robbins TW (1991) Dissociable roles of the ventral, medial and lateral striatum on the acquisition and performance of a complex visual stimulus-response habit. Behav Brain Res 45:147-161.

Reynolds JN, Hyland BI, Wickens JR (2001) A cellular mechanism of reward-related learning. Nature 413:67-70.

Sanchis-Segura C, Jancic D, Jimenez-Minchan M, Barco A (2009) Inhibition of cAMP responsive element binding protein in striatal neurons enhances approach and avoidance responses toward morphine-and morphine withdrawal-related cues. Front Behav Neurosci 3:30.

Sandi C, Pinelo-Nava MT (2007) Stress and memory: behavioral effects and neurobiological mechanisms. Neural Plast 2007:78970.

Schwabe L, Oitzl MS, Philippsen C, Richter S, Bohringer A, Wippich W, Schachinger H (2007) Stress modulates the use of spatial versus stimulus-response learning strategies in humans. Learn Mem 14:109_ 116.

Schwabe L, Schächinger H, de Kloet ER, Oitzl MS (2010a) Corticosteroids operate as a switch between memory systems. J Cogn Neurosci 22:1362-1372.

Schwabe L, Schächinger H, de Kloet ER, Oitzl MS (2010b) Stress impairs spatial but not early stimulus-response learning. Behav Brain Res 213:50-55.

Shimizu-Albergine M, Ippolito DL, Beavo JA (2001) Downregulation of fasting-induced cAMP response element-mediated gene induction by leptin in neuropeptide $\mathrm{Y}$ neurons of the arcuate nucleus. J Neurosci $21: 1238-1246$

Skinner BF (1934) A discrimination without previous conditioning. Proc Natl Acad Sci U S A 20:532-536.

Squire LR (1998) Memory systems. C R Acad Sci III 321:153-156.

Sun W, Rebec GV (2006) Repeated cocaine self-administration alters processing of cocaine-related information in rat prefrontal cortex. J Neurosci 26:8004-8008.

Suri RE, Schultz W (1999) A neural network model with dopamine-like reinforcement signal that learns a spatial delayed response task. Neuroscience 91:871-890.

Taylor JR, Birnbaum S, Ubriani R, Arnsten AF (1999) Activation of cAMPdependent protein kinase A in prefrontal cortex impairs working memory performance. J Neurosci 19:RC23(1-5).

Valentin VV, Dickinson A, O'Doherty JP (2007) Determining the neural substrates of goal-directed learning in the human brain. J Neurosci 27:4019-4026.

Voermans NC, Petersson KM, Daudey L, Weber B, Van Spaendonck KP, Kremer HP, Fernández G (2004) Interaction between the human hippocampus and the caudate nucleus during route recognition. Neuron 43:427-435.

Walters CL, Blendy JA (2001) Different requirements for cAMP response element binding protein in positive and negative reinforcing properties of drugs of abuse. J Neurosci 21:9438-9444.

Widnell KL, Self DW, Lane SB, Russell DS, Vaidya VA, Miserendino MJ, Rubin CS, Duman RS, Nestler EJ (1996) Regulation of CREB expression: in vivo evidence for a functional role in morphine action in the nucleus accumbens. J Pharmacol Exp Ther 276:306-315.

Wise RA (2002) Brain reward circuitry: insights from unsensed incentives. Neuron 36:229-240.

Wise RA (2004) Dopamine, learning and motivation. Nat Rev Neurosci 5:483-494.

Yang HY, Pu XP (2009) Chronic morphine administration induces overexpression of aldolase $\mathrm{C}$ with reduction of CREB phosphorylation in the mouse hippocampus. Eur J Pharmacol 609:51-57.

Yin HH, Knowlton BJ (2006) The role of the basal ganglia in habit formation. Nat Rev Neurosci 7:464-476.

Zheng P, Zhang XX, Bunney BS, Shi WX (1999) Opposite modulation of cortical $N$-methyl-D-aspartate receptor-mediated responses by low and high concentrations of dopamine. Neuroscience 91:527-535.

Zhou LF, Zhu YP (2006) Changes of CREB in rat hippocampus, prefrontal cortex and nucleus accumbens during three phases of morphine induced conditioned place preference in rats. J Zhejiang Univ Sci B 7:107-113. 